\title{
Automated Answering for Subjective Examination
}

\author{
Asmita Dhokrat \\ Dept. of .Computer Science \\ and Information Technology \\ Dr. Babasaheb Ambedkar \\ Marathwada University, \\ Aurangabad, MS, India
}

\author{
Gite Hanumant R. \\ Dept. of .Computer Science \\ and Information Technology \\ Dr. Babasaheb Ambedkar \\ Marathwada University, \\ Aurangabad, MS, India
}

\author{
C.Namrata Mahender \\ Dept. of .Computer Science \\ and Information Technology \\ Dr. Babasaheb Ambedkar \\ Marathwada University, \\ Aurangabad, MS, India
}

\begin{abstract}
Online courses are getting popular among students. Trends of objective examination for such courses are already available but many courses require assessment in traditional way so that the subject understanding of the candidate can be evaluated which requires subjective assessment i.e. descriptive based examination. Thus in our paper we are focusing on the inference process required for development of such type of systems. Our system is able to assess one word and one sentence based answer with more than $80 \%$ of efficiency. While answering single sentence answers paraphrasing is consider for assessing the variations occurring due to the use of vocabulary.
\end{abstract}

Keywords: Online Descriptive examination, Subjective Examination, Synonym, Discourse.

\section{INTRODUCTION}

Today the World Wide Web has become the major source of information for everyone from a general user to researcher for fulfilling their information needs [1]. More than 1.5 million people are benefited by the online courses. Every course can be considered to have following component.

- Learning, Understanding

- Delivery

- Course material

- Assessment or evaluation

Generally the online education courses have objective based answering system which is quite easy to evaluate and maintain but if compared to the courses done on university level that need to test the concept level of a student and in a traditional education system. Subjective or descriptive examination plays an important role.

There are many online examination systems in the market: A web based examination and evaluation system for computer education [2]. Mixed method validation of pedagogical concepts for an intercultural online learning environment [3], online annotation research and practices [4], Online network with computer assisted personalized approach, Online examination system at Grambling state university [5] Web based educational technologies allow education to study how students learn and which learning strategies are most effective. The online examination systems available have their uniqueness and solve specific problem for the online education like:

- Store the questions and answers in database.

- Display result after submit the examination.
- Multiple or single-choice answers, and fill in blank with correct answer.

- Base on internet-based test.

- Study guides.

- Use for a specific type of examination such as ACT, MSCE, JAVA Certificate, etc.

- Generate test answer program.

Our systems works on descriptive examination by considering one word answer to one sentence answer assessment.

\section{ONLINE SUBJECTIVE EXAMINATION}

Subjective examination means assessing answers which have Descriptive, Define or Explain types of question; such examinations are to evaluate the conceptual grasping level of a candidate to how much the concepts are understood in a particular subject [6].

\subsection{Online Descriptive Question Data Type}

- Define: explain the meaning and (often) provide an appropriate example.

- Describe / illustrate: present the main points with clear examples that enhance the discussion.

- Differentiate / distinguish: present the differences between two things.

- Discuss / explain: present the main points, facts, and details of a topic; give reasons.

- Enumerate /List / identify/ Outline: write a list of the main points with brief explanations.

- Interpret: present your analysis of the topic using facts and reasoning.

- Justify / prove: present evidence and reasons that support the topic.

- Summarize: briefly state the main ideas in an organized manner.

- Trace: state the main points in logical or chronological order.

\subsection{Issues in Online Descriptive Examination System}

Main issue of subjective examination is the explanation, example and description given by students which may have different words i.e. synonym used to frame the sentence but they must have the same meaning and point's necessary for the answer to be correct.

Second issue is the size or the length of the sentences in an answer. Indirectly the answer vary person to person, which requires huge efforts to put them into the category according to context. 
- The simple question can be seen in multiple way of answering and a single answer matches as per the sentence with other.

- If semantically checked it has the same meaning for the answer.

- We can know that because we are state the context of the question as well as the real context in which we want the answer. It becomes easy for us to set the target answer for question and model or extract every answer into its proper context as per the target answer (model answer).

If we consider the problem of online subjective examination it needs a good language command many a times may be literature or technical question paper thus it can be purview under Natural Language Processing. In our work we have considered the Chomsky hierarchy as base for our model.

\subsection{Our System}

We have developed the online assessment of descriptive question based on the tutorial we developed. The subject or the course for which we have framed the questions and model answers is on operating system.

According to our view questions have been classified in the following two categories:

\subsubsection{Question based answer}

The answer depends upon what is simply stated in the question.

For Ex: - What is your name?

The main objective of this question is Name.

Answer: -

C1- My name is Asmita.

C2- I am Asmita.

C3- I am known as Asmita.

C4- My parent kept my name Asmita.

C5- You may call me Asmita.

Here the answer is same but the way of answering is different.

\subsubsection{Situation based answering}

The answer is based on situations.

For Ex: - Do you have watch?

Answer: -

C1- I have.

\section{C2- Its 2 O'clock}

C3- It's my good time or it's my bad time.

Here the ways of answering as well as answer both are different.

The question answering system which we have modeled actually consists of three types of answering.

\subsubsection{Three ways of answer}

\subsubsection{Yes / No or True or False answer}

The inference engine does not have much to do rather than just matching the correct option with the candidate answer.

\subsubsection{One word}

In one word answer we face problem of word matching problem in such cases of misspelling if done we have provided the minimum error acceptability like "server" misspelled as "serve" can be consider as answer but words like data with date is not acceptable. The error flexibility actually depends according to the subject for which the process is developed. So an intelligent reasoning is provided while interfacing.

\subsubsection{One sentence}

One sentence answer needs a lot of attention for this two different accessing is done which is further discussed below in detail.

\subsection{Synonym based}

Here in this method the way of answering is synonym based means the candidates used different synonyms for a particular word which is given to model answer. In this example we have shown uses of synonyms for the word for quick like fast and rapid, for predictable like knowable, for response like reply and for events like actions by candidates.

For Example: - What is main objective of real-time operating system?

Model Answer: - Quick and predictable response to events.

Answer: -

C1- Quick and predictable response to events

C2- Fast and predictable response to events

C3 - Rapid and knowable response to events

C4 - Quick and predictable reply to action

C5- Fast knowable reply to action

\subsection{Lexical/Structured}

In this stage the answer depends upon the thinking of the candidates. Answer meaning is same but the way of answering is different. Here the model answer is different and candidates answer is also different but both answers are right only approach is different.

Q1. What is main objective of real time operating system?

Ans: -

1) Quick predictable response to events.

2) Return correct result within time constraints.

3) Responds to input instantly.

4) Response time very short.

\section{INFERENCE PROCESS}

The inference process follows the following steps.

1) First the question style checked if it is yes / no format than the model answer related to those questions are called up for appropriate matching.

2) If it is one word answers then again the model answer are called up and a matching process is carried out. In case of spell mistake we applied hamming distance to calculate the rate of error, if its distance from the model answer is less than two we accept it as correct else the word is rejected an the answer is accessed as wrong.

3) One sentence based answer have to firstly check if they are in the same sequence [sequential form] as in the given model answer. Then we evaluate it as correct but for following case the process ignores if conjunctions or prepositions like 'is', 'the', 'an', 'and' if are missing are ignored and term the candidate answer as correct. 
4) If sentential form is different then we check for its synonym representation provided in our knowledge base system.

- If sentential words used like "part" can be written as component such cases are checked using WordNet dictionary if appropriate meaning match is found the answer is accepted else rejected.

- The whole sentence, sentential meaning is checked with already stored information in our knowledge base, if those representations have same semantic structure then it is termed to be right else wrong. For considering the model answer in differential form are written and those are termed by ranking using the confidence factor provided using appropriate references like books articles for that answer.

\subsection{Assessment Process}

In our work we have considered Eight one word based, Twelve one sentence based question and Ten candidates were asked to answer the question, while evaluation in our work we have consider seven criteria that are related to discourse.

- Cohesion - grammatical relationship between parts of a sentence essential for its interpretation.

- Coherence - the order of statements relates one another by sense.

- Intentionality - the message has to be conveyed deliberately and consciously.

- Acceptability - indicates that the communicative product needs to be satisfactory in that the audience approves it.

- Informativeness - some new information has to be included in the discourse.

- Situationality - circumstances in which the remark is made are important.

- Intertextuality - reference to the world outside the text or the interpreters' schemata [7].

\subsubsection{Assessment of one word}

Direct the model answer is compared with the candidate answer. If hamming distance of these is zero or less than two the answer accepted as correct else answer is rejected as wrong. Results of simple answer or straight answer are shown in Table 1 .

Table1- Simple Answers

\begin{tabular}{|c|l|c|c|}
\hline $\begin{array}{c}\text { Q. } \\
\text { No. }\end{array}$ & \multicolumn{1}{|c|}{ Keywords } & $\begin{array}{c}\text { R. } \\
\text { Ans }\end{array}$ & $\begin{array}{c}\text { W. } \\
\text { Ans }\end{array}$ \\
\hline Q1 & Long term & 10 & 0 \\
\hline Q2 & medium term & 10 & 0 \\
\hline Q3 & New & 10 & 0 \\
\hline Q4 & Linked list or circular list & 7 & 0 \\
\hline Q5 & short term & 10 & 0 \\
\hline Q6 & medium term & 8 & 2 \\
\hline Q7 & $\begin{array}{l}\text { Job, ready, device, waiting, I/O, } \\
\text { Priority, }\end{array}$ & 6 & 4 \\
\hline Q8 & Windows CE, Minix 3 & 10 & 0 \\
\hline Q9 & Interrupt, system call & 10 & 0 \\
\hline Q10 & Kernel & 10 & 0 \\
\hline
\end{tabular}

\subsubsection{One Sentence}

One sentence can vary in length from person to person and even the way of expression and words used while answering as it depends on the strength of the vocabulary of the examining candidate. Thus before assessing we have provided a knowledge base which is nothing but rule base representation of various ways and style of answering with same sentential meaning which is shown in Table 2 and Table 3.

\section{a. Synonym based}

Table 2- Synonym based answer

\begin{tabular}{|c|l|c|c|}
\hline $\begin{array}{c}\text { Q. } \\
\text { No. }\end{array}$ & \multicolumn{1}{|c|}{ Keywords } & $\begin{array}{c}\text { R. } \\
\text { Ans }\end{array}$ & $\begin{array}{c}\text { W. } \\
\text { Ans }\end{array}$ \\
\hline Q1 & $\begin{array}{l}\text { a) Software that handles computer hardware, } \\
\text { b) Intermediator between user hardware, }\end{array}$ & 8 & 2 \\
\hline Q2 & $\begin{array}{l}\text { a) A process is a the unit of work in a system } \\
\text { b) Process is a program in execution }\end{array}$ & 10 & 0 \\
\hline Q3 & $\begin{array}{l}\text { a) The process is waiting for some event to } \\
\text { occur } \\
\text { b) When process is in running as some } \\
\text { interrupt are created then process is waiting } \\
\text { state. }\end{array}$ & 7 & 3 \\
\hline Q4 & $\begin{array}{l}\text { a) Selecting processes from these queues } \\
\text { b) A process is migrates between various } \\
\text { scheduling queues throughout its lifetime. }\end{array}$ & 8 & 2 \\
\hline Q5 & $\begin{array}{l}\text { a) Compact and extremely efficient by design } \\
\text { b) They are designed to operate on small } \\
\text { machines like PDAs. }\end{array}$ & 6 & 4 \\
\hline
\end{tabular}

\section{b. lexical / structure based}

Table3- Simple Lexical / Structure Based Answer

\begin{tabular}{|c|l|c|c|}
\hline $\begin{array}{c}\text { Q. } \\
\text { No. }\end{array}$ & \multicolumn{1}{|c|}{ Keywords } & $\begin{array}{c}\text { R. } \\
\text { Ans }\end{array}$ & $\begin{array}{c}\text { W. } \\
\text { Ans }\end{array}$ \\
\hline Q1 & $\begin{array}{l}\text { Manages/handle computer/CPU/ } \\
\text { processor/ system between/among, } \\
\text { user/client }\end{array}$ & 5 & 5 \\
\hline Q2 & $\begin{array}{l}\text { Quick/fast/rapid/ immediate, Predictable } \\
\text { /knowable, Response/ reply/reaction } \\
\text { answer, Events/action }\end{array}$ & 8 & 2 \\
\hline Q3 & $\begin{array}{l}\text { Group/cluster/set independent/self } \\
\text { computer/ CPU/ processor/system/make/ } \\
\text { create/build/ appear/become/visible/show/ } \\
\text { single/distinct/ CPU/computer/processor/ } \\
\text { system }\end{array}$ & 8 & 2 \\
\hline Q4 & $\begin{array}{l}\text { Program/agenda/plan/in/during/execution/ } \\
\text { finishing/ completion }\end{array}$ & 10 & 0 \\
\hline Q5 & $\begin{array}{l}\text { some/few/various/several/event/result/occ } \\
\text { urrence /interrupt/ occur/happen/ takes } \\
\text { place }\end{array}$ & 7 & 3 \\
\hline Q6 & $\begin{array}{l}\text { some/few/various/several/process/procedu } \\
\text { re/course/method/running/ executes/at/by/ } \\
\text { on/ all/ every/utilization/use/operation }\end{array}$ & 6 & 7 \\
\hline Q8 & $\begin{array}{l}\text { select/few/various/several/processes/proce } \\
\text { dure/course/method/queues/row/line } \\
\text { compact/solid/extremely/very/tremendousl } \\
\text { ign/plan/intend }\end{array}$ & 7 & 3 \\
\hline
\end{tabular}

\section{ANALYSIS}

\subsection{One Word Answer}

- Normally correct due to the straight forward presence of answer in tutorial. So results achieved were $100 \%$, ignoring the spell mistake. 


\subsection{One Sentence}

\subsubsection{Synonym based}

Available lexicons in tutorial were replaced by their synonyms while answering. Such case needed WordNet dictionary and result achieved were $100 \%$ but such cases were rarely found in our candidate answer dataset.

\subsubsection{Lexical/ Structure based}

Multiple expressions for e.g. active to passive, alteration as multiple way of reasoning provided while answering. We achieved $75 \%$ result mainly due to the complexity which was found while extracting the pattern and its reason analysis showed it was due to incomplete occurrence of words or occurs in other state then its original state designed by HMM for the model answer as many times it changed the meaning of the answers.

Table 4- Answers with confidence level

\begin{tabular}{|c|l|c|c|c|c|}
\hline $\begin{array}{c}\text { Q. } \\
\text { No. }\end{array}$ & \multicolumn{1}{|c|}{ Model Answer } & $\begin{array}{c}\text { R. } \\
\text { Ans }\end{array}$ & $\begin{array}{c}\text { W. } \\
\text { Ans }\end{array}$ & $\begin{array}{c}(+) \\
\text { Conf. }\end{array}$ & $\begin{array}{c}(-) \\
\text { Conf. }\end{array}$ \\
\hline Q1 & $\begin{array}{l}\text { a) Software that handles } \\
\text { computer hardware, } \\
\text { b) Intermediator between } \\
\text { user hardware, }\end{array}$ & 5 & 5 & $50 \%$ & $50 \%$ \\
\hline Q2 & $\begin{array}{l}\text { a) quick predictable } \\
\text { response to events }\end{array}$ & 8 & 2 & $80 \%$ & $20 \%$ \\
\hline Q3 & $\begin{array}{l}\text { a) Group independent } \\
\text { computers make them } \\
\text { appear to single } \\
\text { computer }\end{array}$ & 8 & 2 & $80 \%$ & $20 \%$ \\
\hline Q4 & $\begin{array}{l}\text { a)A process is a the unit } \\
\text { of work in a system } \\
\text { b) Process is a program } \\
\text { in execution }\end{array}$ & 10 & 0 & $100 \%$ & $0 \%$ \\
\hline Q5 & $\begin{array}{l}\text { a)The process is waiting } \\
\text { for some event to occur }\end{array}$ & 7 & 3 & $70 \%$ & $30 \%$ \\
\hline Q6 & $\begin{array}{l}\text { a) Some process running } \\
\text { at all times to maximize } \\
\text { CPU utilization. }\end{array}$ & 6 & 4 & $60 \%$ & $40 \%$ \\
\hline Q7 & $\begin{array}{l}\text { a)Job, ready, device, } \\
\text { waiting, i/o, priority }\end{array}$ & 6 & 4 & $60 \%$ & $40 \%$ \\
\hline Q8 & $\begin{array}{l}\text { a)Selecting processes } \\
\text { from these queues } \\
\text { b) A process is migrates } \\
\text { between various } \\
\text { scheduling queues } \\
\text { throughout its lifetime. }\end{array}$ & 8 & 2 & $80 \%$ & $20 \%$ \\
\hline Q10 & $\begin{array}{l}\text { a)Windows CE, Minix 3 } \\
\text { a)Interrupts }\end{array}$ & 10 & 0 & $100 \%$ & $0 \%$ \\
\hline Q11 & $\begin{array}{l}\text { a)Compact and efficient } \\
\text { by design } \\
\text { b) They are designed to }\end{array}$ & 7 & 3 & $70 \%$ & $30 \%$ \\
\hline a) Kernel & 9 & 0 & $90 \%$ & $10 \%$ \\
\hline
\end{tabular}

\section{CONCLUSION}

For online examination many software's are available for objective examination but when we concern about subjective or descriptive examination we have limited sources. That's why we model this system as it is even need of time. We have discussed and solved some issues which were hurdles while building subjective examination system.

The main things which we contributed while working was providing the conceptual view of answering and modeling it into two scenario as question based and context based, which helped much for processing. Cognitive and computation based algorithm was designed to extract patterns from answers for comparing candidate answer with model answer while evaluation processes. The whole things were broadly divided into two spectrum i.e. straight forward or simple answer and paraphrased answers.

Python with NLTK tool kit were used for matching answers, and for synonymy paraphrasing we directly considered word wide dictionary i.e. WordNet. We notice that one word answers are generally $100 \%$ correct as they have only two possibilities either right or wrong but when we consider one line answer questions like definitions they have $85 \%$ to $90 \%$ correct answers as in this type of questions candidates generally copy paste the same answer as in the tutorial.

We have not considered multiline answers, figures (diagrams), examples, abbreviations, and more contextual different references these are also the limitations of our system.

\section{REFERENCES}

[1] Judy McKimm, Carol Jollie, Peter Cantillon, "ABC of learning and teaching Web based learning" http://www.bmj.com/

[2] Yuan, Zhenming, et al. A Web-Based Examination and Evaluation System for Computer Education. Washington, DC: IEEE Computer Society, 2006.

[3] Effie Lai-Chong Law, et al. Mixed-Method Validation of Pedagogical Concepts for an Intercultural Online Learning Environment. New York: Association for Computer Machinery, 2007.

[4] Lan, Glover, et al. Online Annotation- Research and Practices. Oxford UK: Elsevier Science Ltd, 2007.

[5] Sophal Chao and Dr. Y.B Reddy Online examination Fifth International Conference on Information Technology: New Generations, 2008

[6] Hanumant R. Gite, C.Namrata Mahender "Representation of Model Answer: Online Subjective Examination System" National conference NC3IT2012 Sinhgad Institute of Computer Sciences Pandharpur.

[7] "Discourse analysis" website http://www.tlumaczenia _angielski.info/linguistic/discourse.htm 